Article

\title{
Evaluation of the Emission Impact of Cold-Ironing Power Systems, Using a Bi-Directional Power Flow Control Strategy
}

\author{
Carlos A. Reusser ${ }^{1, t, *}$ (D) and Joel R. Pérez ${ }^{2, t}$ \\ 1 School of Electrical Engineering, Pontificia Universidad Catolica de Valparaiso, Valparaíso 2950, Chile \\ 2 Mechanical Engineering Department, University College London, London WC1E 6BT, UK; \\ joel.osses.10@ucl.ac.uk \\ * Correspondence: carlos.reusser@pucv.cl \\ + These authors contributed equally to this work.
}

check for updates

Citation: Reusser, C.A.; Pérez, J.R. Evaluation of the Emission Impact of Cold-Ironing Power Systems, Using a Bi-Directional Power Flow Control Strategy. Sustainability 2021, 13, 334. https://doi.org/10.3390/su13010334

Received: 1 December 2020 Accepted: 22 December 2020 Published: 31 December 2020

Publisher's Note: MDPI stays neutral with regard to jurisdictional clai$\mathrm{ms}$ in published maps and institutional affiliations.

Copyright: $\odot 2020$ by the authors. Licensee MDPI, Basel, Switzerland. This article is an open access article distributed under the terms and conditions of the Creative Commons Attribution (CC BY) license (https:// creativecommons.org/licenses/by/ $4.0 /)$.

\begin{abstract}
Even though cold ironing is not a new technology applied to reduce the impact of emissions from ships at berth, commonly used arrangements for shore-side power substations only allow a unidirectional power flow, from port to ship side. Although these applications have a positive contribution to port community health and global reduction of greenhouse gases (GHG), especially when the energy is supplied from renewable sources, emissions during loading/unloading operations are directly related to the operating profiles of auxiliary engines of a ship. The present work evaluates a ship's emission impact when applying cold-ironing technology using a bi-directional power flow control strategy while at berth, thus optimizing the auxiliary engine operating profile and enabling regeneration into the port installations. The methodology applied considers the establishment of the operational profile of the ship, the adaptation and use of carbon intensity indicators (CII) used by the International Maritime Organization (IMO) to evaluate the impact of shipping, and the strategy considering the capacities of the ship to obtain and provide electric power from and to the port when at berth. Results show that the strategy can be applied to any ship with a high demand for electric power while at berth, and that the adaptation and use of different CIIs allows operational profiles of electric power generation on board to be optimized and to reduce emission generation, which affects port community health.
\end{abstract}

Keywords: cold ironing; emissions impact; electric power generation; back-to-back power converter; optimization algorithm

\section{Introduction}

Cold-ironing technology is well established in shipping transport. It is a port-based emission-reduction technology that reduces emissions generated from the auxiliary engines of a ship using shore-based electric power. It first appeared when ships used coal-fired engines. Specifically, when a ship was berthing and it was not necessary to continue to feed the fire, the engines would cool down completely. This is where this technology got its name. Presently, however, when ships are berthed, they use auxiliary engines to support loading/unloading of cargo and the port services [1]. This must be taken into consideration, as it generates emissions that affect the port community health, as well as noise and vibrations.

To mitigate these issues, cold ironing offers a solution. The emission generations from the ship are reduced; however, they are generated from the port. When the energy source to provide electric power to support the ship is a non-conventional renewable energy (NCRE) source, the emissions are mitigated.

In cold ironing, the ship turns off its auxiliary engines while berthed, and plugs into an onshore power source. The ship power load is then transferred to the shore-side power supply without disrupting on-board services. With this process, the loading/unloading 
of cargo and the ship port services can still receive continuous electrical power. The operational profile service of the ship must be taken into consideration when analyzing the benefits of using this technology. This study showcases an approach considering the adaptation and use of the most constrained carbon intensity indicators (CIIs) from the International Maritime Organization (IMO) to evaluate the operational emission impact of cold ironing when considering the use of a bi-directional power flow control strategy. The main emissions are $\mathrm{CO}_{2}, \mathrm{NO}_{\mathrm{x}}$ and $\mathrm{SO}_{\mathrm{x}}$.

\section{Cold-Ironing System}

Cold ironing goes by a variety of names: shore-to-ship power supply, alternative maritime power, onshore power supply, and shore-side electricity. The variations in name are strictly due to the usage adopted by the different organizations involved in this portbased emissions reduction technology application and has no other significance. The implementation of cold ironing has been addressed as a short-term technology application from the IMO to be applied to reduce the impact of shipping [2,3]. Cold ironing is an option that considers the impact of shipping at port playing a big role in the decarbonization of them and surrounded areas. [4,5]

Even though this is an old technology, it has not been massively applied yet, because of the low trade-off in GHG emissions. The ship reduces its emissions when turning off its auxiliary engines, but the power generation must be supplied by the port services, which means that global GHG emissions are still being generated. To be properly considered to be a technology that reduces emissions from shipping, the port needs to secure that the electric power to support the ships loads, is been generated by using wind, solar, small hydro, tides, geothermal heat and biomass as (NCRE) sources [6,7].

In this matter, the IMO considers the use of the energy efficiency design index (EEDI) to evaluate the efficiency of new ship designs. However, this index only considers design factors with the ship navigating, and not while at berth for its calculation [8]. The ship's electric power demand for services when navigating is quite different from the demand while at berth, therefore the need to evaluate emissions using a different approach. The IMO considers the use of CIIs, which are indicators of the efficiency of a ship when operating, which are used to monitor the performance of ships emissions, considering factors that vary over time such as: the distance and time sailed, average speed, amount of cargo transported, loading condition, weather conditions and the energy required while at berth. The last one associated with cold ironing and the main reason to consider the adaptation and use of CIIs in this work. CIIs evaluation uses the fuel consumption of the main and the auxiliary systems on board, at different operational conditions over the transport work. Transport work relates the amount of cargo transported over distance, which could not be considered while at berth. However, when at berth, the ship is still generating emissions from auxiliary engines. On the other hand, fuel consumption is related to the time of the auxiliary engine's operation at port. Therefore, when considering the transport work of the ship as the time spent at berth, the CIIs can be applied to evaluate the impact of cold ironing.

The most common CIIs from the IMO are the energy efficiency operational indicator (EEOI) and the annual efficiency ratio (AER). These two indicators are adapted and considered in this study to evaluate the operational efficiency when applying the cold-ironing technology [9].

The EEOI is the ratio between the mass of $\mathrm{CO}_{2}$ emitted per unit of transport work, transport work being the key factor to denote an operational efficient ship i.e., a ship with a high payload use, when compared to ballast voyages which have a lower EEOI, therefore being more efficient. The AER, on the other hand, is the ratio between the mass of $\mathrm{CO}_{2}$ emitted per maximum unit of transport work, being the key factor to denote an operational efficient ship, assuming the ship fully loaded on every voyage. The difference between both indicators corresponds to the efficiency when at ballast condition. Nonetheless this difference, these CIIs become the same, when time is used as the transport work while at 
berth. Under this consideration, EEOI is one of the monitoring tools to be considered in the mandatory ship energy efficiency management plan (SEEMP), which is to be applied to new and existing ships.

The SEEMP is an operational measure that establishes a mechanism to improve energy efficiency of a ship, in a cost-effective manner [10] and is mandatory to be applied to new and existing ships. SEEMP suggest using the EEOI as the operational indicator to evaluate the efficiency of a ship at service, therefore it has been used as the CII in this work. Equation (1) shows the general EEOI equation to evaluate the operational emissions from a ship, considering time as the transport work factor, while evaluating the performance of the ship at berth.

$$
E E O I=\frac{\sum_{j} F_{C j} C_{F j}}{\Delta t}
$$

where: $j$ is the fuel type, non-dimensional; $F_{C j}$ is the mass of consumed fuel $j$, measured in $\mathrm{g}$ Fuel/ $\mathrm{h} ; \mathrm{C}_{F j}$ is the fuel mass to $\mathrm{CO}_{2}$ mass conversion factor, for fuel $j$, measured in $\mathrm{g}$ $\mathrm{CO}_{2} / \mathrm{g}$ Fuel, and $\Delta t$ being the time spent at berth in hours. The fuel consumed on board the ship is Heavy Fuel Oil (HFO), which has a $C_{F}$ of $3.114 \mathrm{~g} \mathrm{CO}_{2} / \mathrm{g}$ Fuel. Factors relating $\mathrm{NO}_{x}$ and $\mathrm{SO}_{x}$ emissions to specific fuel consumption are used to get an overall evaluation of the main emissions from shipping.

The estimation of the efficiency and the fuel consumption of the auxiliary engines at berth is possible to know and to be used into the EEOI because evaluates based on the electric power table (EPT) of the ship. The EPT is a table of electric power consumption, related to the auxiliary engines, of all the electric equipment installed on board of the ship differentiating their use while navigating and at berth. The EPT provides the demand to keep the ship operating at berth providing a detailed scheme of the demand and possible contribution of the auxiliary engines to the port grid. The EPT is an equivalence of the product of service factors divided by load, duty, and time [8].

\subsection{Classical Cold-Ironing Configuration}

The classical cold-ironing configuration consists of multiple power feeder circuits, to supply the required power with the ship alongside at berthing. In this condition, power requirements will differ, depending on the vessel type and size. Table 1 presents the power requirements at berth according to the IEEE 80005-1 standard [11,12].

Table 1. Power requirements at berth.

\begin{tabular}{lcc}
\hline Ship Type & Voltage [kV] & Power [MVA] \\
\hline Cruise ships & 6.6 or 11 & $16-20$ \\
Container ships & 6.6 & 7.5 \\
LNG carriers & 6.6 or 11 & 10.7 \\
Ro-Ro ships & 11 & 6.5 \\
Tankers & 6.6 & 7.2 \\
\hline
\end{tabular}

The tankers case is particularly sensitive to cold ironing. Latest designs are showing the use of a cargo system based on electric drivers, instead of classical steam drivers. Because the cargo system is demanded at berth mostly, the use of cold ironing has a significant impact in the reduction of the electric power generation on board [13-16]. This change and impact of emissions needs to be considered through a CIIs and EPT analysis. Because of to the previously made considerations, the tanker is the type of ship selected in this study to evaluate the impact of the cold-ironing strategy.

Due to the diversity of ship builders, on-board power supply and distribution systems may be specified for 50 or $60 \mathrm{~Hz}$. This fact adds an additional requirement for the coldironing configuration, due the on-board and shore electric frequency diversity. To deal with this problem and to ensure voltage and frequency supply specifications, a power converter and a power transformer are required in the shore electric sub-station. Figure 1 shows a diagram of a typical cold-ironing shore sub-station [17]. 


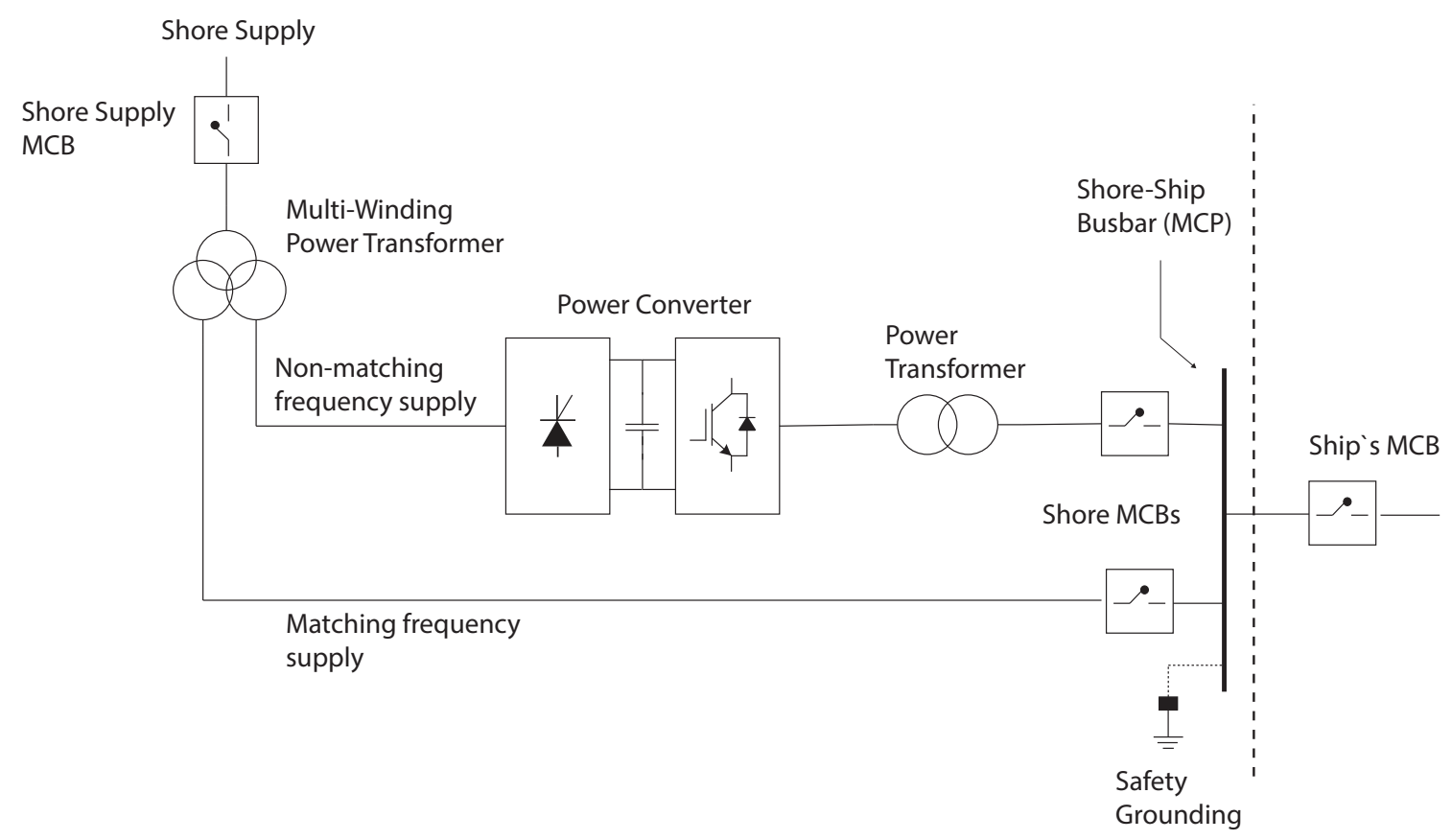

Figure 1. Typical cold-ironing shore sub-station.

As shown in Figure 1, in the classical configuration of the cold-ironing system, the shore supply is fed to the ship via two different distribution lines, using a multi-winding power transformer. One of the output three-phase windings is connected directly to the shore-ship busbar, main coupling point (MCP), which is used when the ship and the shore supply have the same operational frequency. The second output is connected to a power converter, to convert the shore supply frequency, to that required by the ship's electrical loads. This arrangement introduces the need for a close/open position selector, to ensure that both main circuit breakers (MCBs) are prevented to operate in the close position, at the same time.

It must be noted that this configuration considers a unidirectional power flow, from the shore supply to the ship and not vice-versa. This fact introduces the following drawbacks:

- Requires large multi-winding transformers.

- Build-up of circulating currents through the secondary and tertiary windings of the multi-winding transformer, with only one feeding circuit in use.

- Uses separate supply circuits, depending on the ship's operational frequency.

- Needs additional positioning devices to prevent both MCBs be operated in the close position at the same time.

- Unidirectional power flow.

\subsection{Proposed Bi-Directional Configuration}

The proposed cold-ironing configuration considers a single supply, feeding a back-toback (b2b) power converter as shown in Figure 2.

As shown in Figure 2, in the proposed configuration the multi-winding transformer is replaced by a common power transformer feeding directly the $b 2 b$ power converter. The output of the inverting stage of the power converter, ensures controlled voltage and frequency at the MCP, thus fulfilling the voltage level and frequency rating of the ship's power distribution system. The $\mathrm{b} 2 \mathrm{~b}$ converter arrangement, enables the ability of supplying the ship at unitary power factor, thus suppressing reactive power flow, and enables the capability of bi-directional power flow, from ship to shore supply. 


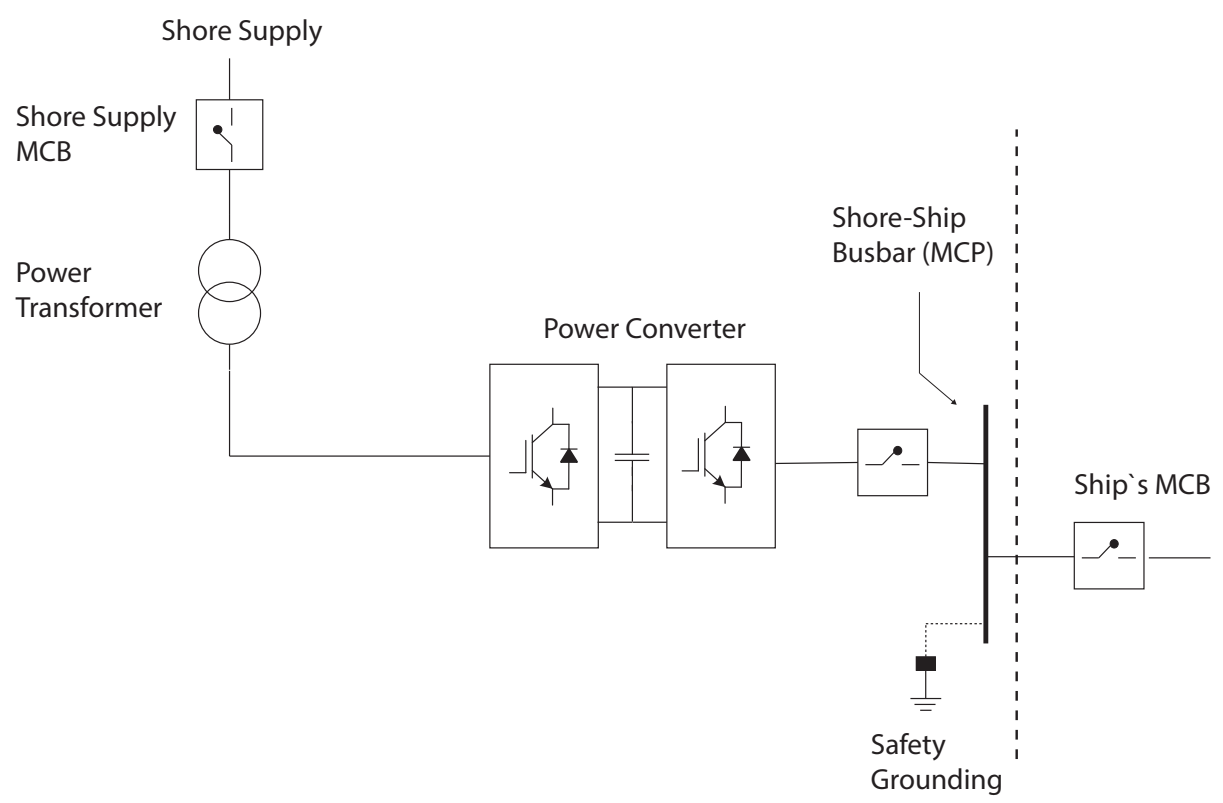

Figure 2. Proposed Cold-Ironing shore sub-station.

This last aspect constitutes the aim of this work. When the ship is at berth operating its machinery for loading/unloading operations, the ship will be running its auxiliary engines to supply the required power. In this condition, the auxiliaries may be operating outside their fuel efficiency operational point, which is around $75-80 \%$ of the maximum continuous rating (MCR), thus contributing to the generation of $\mathrm{CO}_{2}, \mathrm{NO}_{x}$ and $\mathrm{SO}_{x}$ emissions. The ability of controlling the power flow direction, from shore to ship and vice-versa, using the $\mathrm{b} 2 \mathrm{~b}$ configuration, contributes to reduction of emissions, by operating the auxiliary engines within their fuel efficiency power range.

As presented, the main advantages of the proposed configuration are the following:

- Does not require large multi-winding transformers, thus also eliminating the build-up of circulating currents in the secondary winding.

- A single feeding circuit is required.

- The $\mathrm{b} 2 \mathrm{~b}$ converter configuration enables the possibility of bi-directional power flow control. This also contributes to the reduction of emissions of the ship's auxiliary engines.

\section{Optimization Strategy and Control}

Emissions are generated during the process of converting the chemical energy stored in the fuel into mechanical work. This process is represented by means of the stoichiometric reaction of the fuel given in Equation (2).

$$
\mathrm{C}_{m} \mathrm{H}_{n}+\left(m+\frac{n}{4}\right) \mathrm{O}_{2}+p \mathrm{~N}_{2} \rightarrow m \mathrm{CO}_{2}+\frac{n}{2} \mathrm{H}_{2} \mathrm{O}+p \mathrm{~N}_{2}
$$

In this energy conversion process $\mathrm{NO}_{\mathrm{x}}$ and $\mathrm{SO}_{\mathrm{x}}$ emissions are also generated. These emissions are dependent on the $\mathrm{N}_{2}$ present in air and temperature of the combustion process, and the $\mathrm{S}_{2}$ content in fuel, respectively. However, $\mathrm{CO}_{2}$ emissions represent the higher amount of all of them.

During the combustion process the emissions profile exhibits its maximum when operating the auxiliary engine at low and high loads. This characteristic is due because the engine tries to sustain the power output with low air flow, when operating at low loads, and with an excess of fuel, in higher loads. The air to fuel ratio (AFR) requirements reach its lower value within the range of 75 to $80 \%$ of the engine MCR.

The minimum AFR operational point, is also consistent with minimum emissions, thus defining the minimum emissions operation point (MEOP). Within these constrains, the 
optimization strategy is designed to move the operational point of the on-board auxiliary engines towards the MEOP, by controlling the power flow direction in the cold-ironing shore supply, by means of the $\mathrm{b} 2 \mathrm{~b}$ power converter.

Figure 3 differentiates the operating regions of the cold-ironing shore supply, respect to the MEOP of the on-board auxiliary engines.

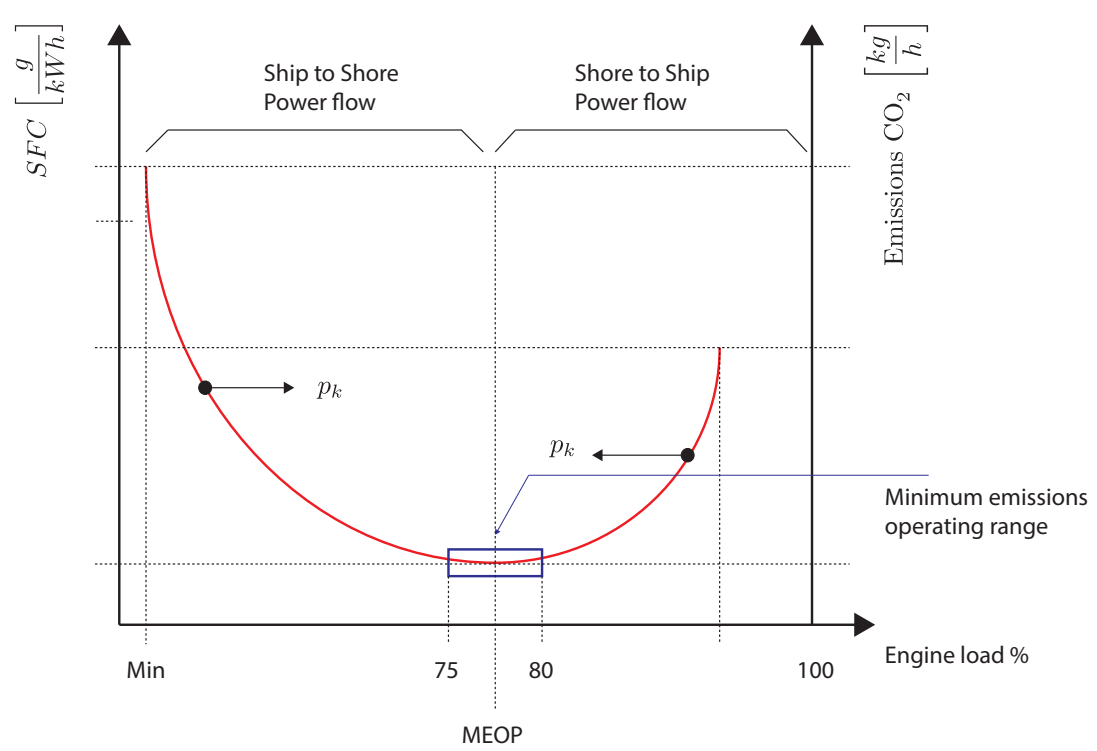

Figure 3. Operating regions of the cold-ironing with bi-directional power control.

When operating in the low load range, power flows from ship to shore, causing the operation point $p_{k}$ move towards the MEOP. On the other hand, when $p_{k}$ is in the high load operation range, the control scheme forces the power flow from shore to ship, causing $p_{k}$ moving towards MEOP. The optimization strategy and the control scheme are discussed in the following subsections.

\subsection{Auxiliary Engine Emissions Model}

The emissions model was built based on the open-source data obtained of a MAN B\&W L23/30H GenSet. By using an appropriate polynomial approximation with squares regression, it was possible to reach an accurate emissions model, which was used in the optimization process. Given $m$ data points $\left\{x_{i} y_{i}\right\}_{i=1}^{m}$ with $x_{i}$ given output power and $y_{i}$ corresponding $\mathrm{CO}_{2}$ emissions rate; the best fit polynomial for the $\mathrm{CO}_{2}$ emissions $e(x)$ could be developed using Equation (3).

$$
e(x)=\sum_{k=0}^{n} \alpha_{k} x^{k} \quad n<m-1
$$

where $\alpha_{k} \forall k$ coefficients may be found by minimizing the least square error using Equation (4).

$$
A^{T} A \boldsymbol{a}=A^{T} \boldsymbol{y}
$$

With the coefficients vector $\boldsymbol{a}=\left[\begin{array}{lll}\alpha_{0} & \ldots & \alpha_{n}\end{array}\right]^{T}$, the sample value vector $\boldsymbol{y}=\left[\begin{array}{lll}y_{0} & \ldots & y_{n}\end{array}\right]^{T}$, and $A$ the Vandermonde matrix, given as in Equations (5) and (6).

$$
\begin{gathered}
A=\left[\begin{array}{ccccc}
1 & x_{1} & x_{1}^{2} & \ldots & x_{1}^{n} \\
1 & x_{2} & x_{2}^{2} & \ldots & x_{2}^{n} \\
\vdots & \vdots & \vdots & \vdots & \\
1 & x_{m} & x_{m}^{2} & \ldots & x_{m}^{n}
\end{array}\right] \forall x_{i} i=1, \ldots, m \\
a=\left(A^{T} A\right)^{-1} A^{T} y
\end{gathered}
$$


Obtaining finally, an $n$ degree polynomial representing the $\mathrm{CO}_{2}$ emissions profile, as given in Equation (7).

$$
y(x)=a_{0}+a_{1} x+a_{2} x^{2}+\ldots+a_{n} x^{n}
$$

\subsection{Emissions Optimization Strategy}

Let us define an arbitrary optimization problem $\phi$ as defined in Equations (8)-(11).

$$
\begin{gathered}
\phi=\langle\mathcal{C}, \mathcal{S}, v, f(x)\rangle \\
\mathcal{C}=x \quad ; x=\left\{x_{0}, \ldots, x_{n}\right\} \\
\mathcal{S}=x \pm \delta \\
v=\min \left\{\left.f(x)\right|_{x \pm \delta}\right\}
\end{gathered}
$$

where $\mathcal{C}$ corresponds to the set of candidate solutions $\mathcal{S}$, with $\mathcal{S} \subseteq \mathcal{C}$ of the optimization problem, $f(x)$ is the objective function, $v$ indicates the optimization sense; $x$ corresponds to the system state and $\delta$ to the variation of the state introduced by the search direction of the optimization strategy.

The implemented optimization strategy is based on the use of a perturb and observe $(\mathrm{P} \& \mathrm{O})$ algorithm, which is a commonly used strategy applied within power flow control structures for grid connected power converters $[18,19]$. The algorithm objective is to reach minimum $\mathrm{CO}_{2}$ emissions, given a certain operational point $p_{k}$, by small variations in the output power reference of the power converter $\Delta P$, and the measurement of the rate of change in the operational point $p_{k}$ which is estimated based on the fuel consumption $g_{k}$. Figure 4 shows the optimization algorithm working principle.

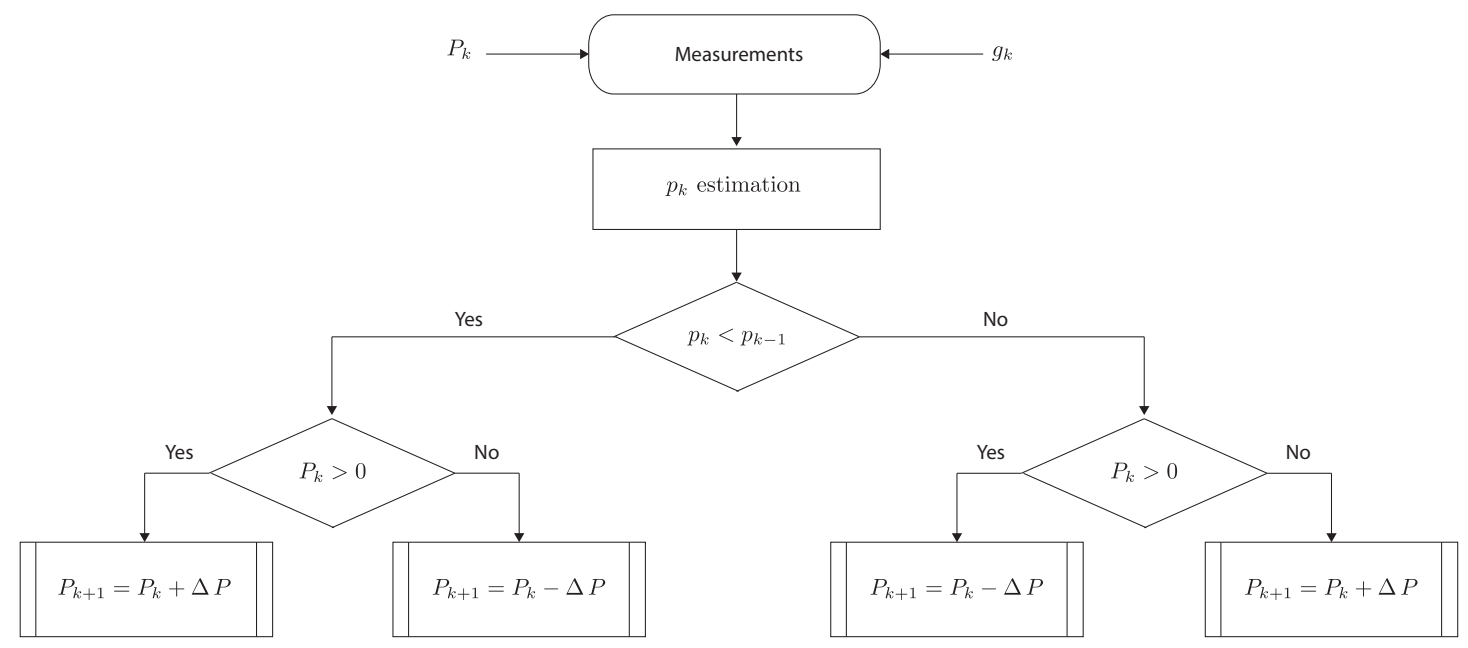

Figure 4. Perturb and Observe optimization strategy algorithm flow diagram.

\subsection{Control Scheme}

The back-to-back (b2b) converter configuration is a widely used topology for high demanding applications where bi-directional power flow and power quality enhancement are required, such as: high power electrical drives, high voltage direct current (HVDC) systems for transmission networks, unified power quality conditioners (UPQC) for power quality improvement, wind generator grid connection, etc. [20,21]. An important characteristic of the $b 2 b$ converter is its capacity to manipulate bi-directional power flows and provide power balance between the rectifier and inverting stages using the energy stored in the DC-link capacitor. 
In this work, a decoupled control strategy for the $\mathrm{b} 2 \mathrm{~b}$ converter has been developed. The input stage, rectifying stage, is controlled as en active front end (AFE) rectifier and the output stage, inverting stage, is controlled as classic inverter without the DC-link voltage control loop, thus it is considered in the rectifying stage control [22].

\subsubsection{Input Stage Control Scheme}

The input stage control is achieved using an active and reactive power-oriented control strategy including DC-link voltage control as stated in [23,24]. To achieve active and reactive components decoupling, a voltage-oriented control (VOC) scheme is used, thus the active and reactive power components, $P$ and $Q$ respectively, in an arbitrary synchronous reference frame $d q$ is given as in Equations (12) and (13).

$$
\begin{aligned}
& P=\frac{3}{2} \mathbb{R} e\left\{v_{i}^{d}\left(i_{i}^{d}+j i_{i}^{q}\right)\right\} \\
& Q=\frac{3}{2} \mathbb{I} m\left\{v_{i}^{d}\left(i_{i}^{d}+j i_{i}^{q}\right)\right\}
\end{aligned}
$$

where $P, Q$ correspond to the grid active and reactive power, respectively and $i_{s}^{d q}$ stands for the grid supply current space vector.

Orientation into the synchronous reference frame $d q$ is achieved by extracting the synchronous angle $\theta_{p}$ which is provided using the virtual-flux space vector $\psi_{i}^{(x y)}$ which is related to the voltage drop in the input inductance $v_{i}^{(x y)}$ as presented in Equations (14) and (15).

$$
\begin{gathered}
\psi_{i}^{(x y)}=\int v_{s}^{(x y)}(t) d t \\
\theta_{p}=\operatorname{atan} 2\left(\psi_{o}^{x}, \psi_{o}^{y}\right)
\end{gathered}
$$

Given a system state variable $x$ defined in the stationary reference frame $x y$, being denoted as $x^{(x y)}$, its rotation into the synchronous reference frame $d q$ is achieved by means of the unitary rotation matrix $U$ which is defined as given in Equations (16) and (17).

$$
\begin{gathered}
U=\left[\begin{array}{cc}
\cos \theta_{p} & \sin \theta_{p} \\
-\sin \theta_{p} & \cos \theta_{p}
\end{array}\right] \\
x^{(d q)}=U x^{(x y)}
\end{gathered}
$$

Considering the rotation expressed in Equation (17), the grid side dynamic model in the $d q$ synchronous reference frame, is presented in Equationss (18) and (19).

$$
\begin{gathered}
v_{s}^{(d q)}=R i_{s}^{(d q)}+L \frac{d}{d t} i_{s}^{(d q)}+\boldsymbol{F} L i_{s}^{(u v)}+v_{g}^{(u v)} \\
\boldsymbol{F}=\left[\begin{array}{cc}
0 & -\omega_{k} \\
\omega_{k} & 0
\end{array}\right]
\end{gathered}
$$

Here $v_{g}^{(d q)}$ corresponds to the grid voltage state space vector. The DC-link dynamic is related to capacitor voltage interaction, which es presented in Equation (20).

$$
C \frac{d}{d t} v_{d c}=i_{s}^{d}-i_{d c}
$$

Here $i_{d c}$ corresponds to the dc current in the DC-link and $v_{d c}$ to the voltage in the capacitor. It must be noted that $i_{d c}$ can be treated as an external perturbation to be rejected by the system controller. Implementation of the grid side control scheme is provided in Figure 5. 


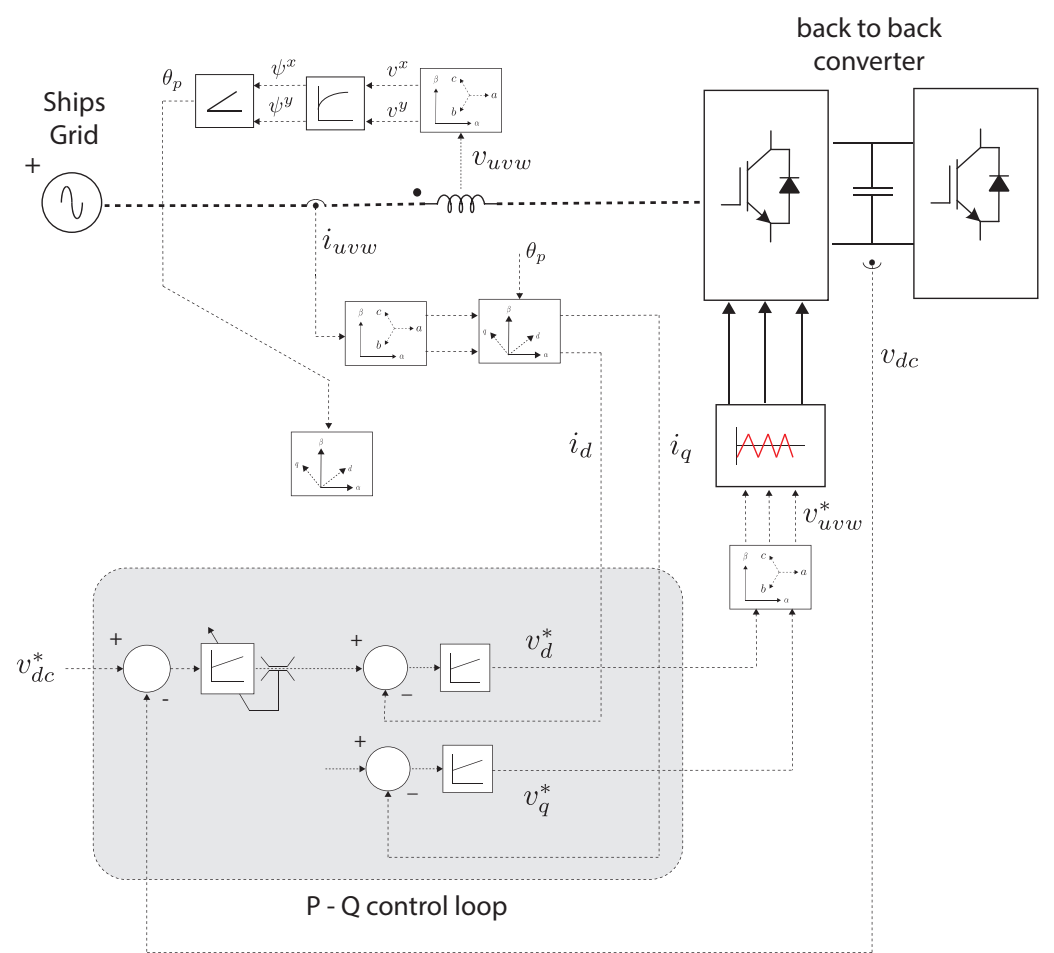

Figure 5. Grid side control loop.

\subsubsection{Output Stage Control Scheme}

Control of the output side, corresponding to the inverting stage of the power converter, is achieved implementing the active and reactive power-oriented control strategy described previously, without the DC-link voltage control scheme.

The shore-side dynamic model in the $u v$ synchronous reference frame, is presented in Equation (21).

$$
v_{o}^{(u v)}=R i_{o}^{(u v)}+L \frac{d}{d t} i_{o}^{(u v)}+\boldsymbol{F} L i_{o}^{(u v)}+v_{g o}^{(u v)}
$$

where $\boldsymbol{F}$ has been presented in Equation (19), $v_{g o}^{(u v)}$ corresponds to the converter output voltage space vector and $v_{g o}^{(u v)}$ to the voltage space vector at the shore-ship busbar; the output current state variable space vector is denoted by $i_{0}^{(u v)}$.

The implementation of the ship side control scheme is provided in Figure 6. As shown, the output of the MEOP optimization scheme, is set as the reference of the active power output of the power converter, while the reactive component, given by $i_{v}^{*}$ is set to zero. 


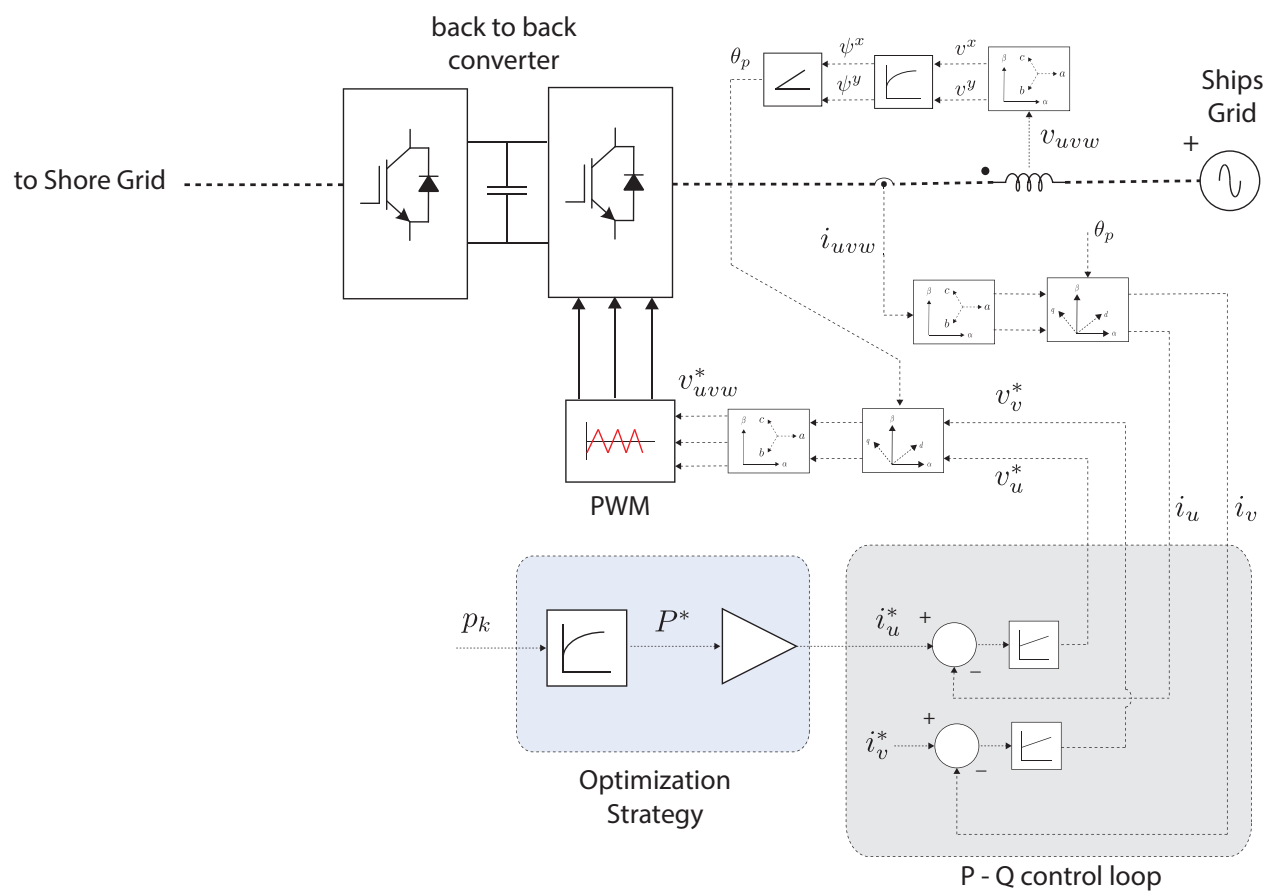

Figure 6. Ships side control loop.

\section{Results}

In this section, the performance of the auxiliary engines and the bi-directional power flow control strategy under cold-ironing implementation are presented. The optimization strategy was developed in C code and implemented using PLECS.

The auxiliary engines emissions were estimated, taking the EEOI equation and applying some operational conditions to the time spent at berth by the ship. A comparison of the emissions profile with and without the proposed strategy, allowed the estimation of the possible emissions reduction that could be achieved.

The data used to simulate the performance of the proposed strategy considers the use of a tanker ship, which has the following specific information: its capacity, speed, cargo transported, distance navigated, power installed, auxiliary power installed, the type of fuel consumed, and its operational profile while at berth. The ship considered was selected from a worldwide database of ships ships [25], but the data was obtained from classification societies as open-source information. The most relevant information while at berth corresponds to the auxiliary power installed. In this case, the auxiliary engines installed on board are 3 but only 2 are enough to cover all ship's power demand. Table 2 presents some details of the auxiliary engines.

When at berth, because of the loading/unloading operations, the auxiliary engines are heavily demanded to cover the needs for the operation, 2 auxiliary engines are always in service leaving the third auxiliary engine in stand-by mode.

Table 2. Ship data for simulation.

\begin{tabular}{ccccc}
\hline Ship Type & Fuel Consumed & Auxiliary Power $[\mathrm{kW}]$ & Engine Model & SFC $[\mathrm{g} / \mathbf{k W h}]$ \\
\hline Tanker & HFO & $1950 \mathrm{~kW}$ & MAN B\&W 5L23/30H & $203.2 \mathrm{~g} / \mathrm{kWh}$ \\
\hline
\end{tabular}

\subsection{Auxiliary Engine Performance}

Results are presented differentiating the performance of the applied strategy of cold ironing the ship at berth considering the performance of the auxiliary engines. The methodology considers the use of the EEOI to show the benefits of the strategy applied, providing a reference to evaluate the operational efficiency of a ship. Results are plotted over two bi-directional cold-ironing (CI) application simulation conditions: the first one without the 
power flow control strategy and the second with the power flow control strategy. For both conditions, the simulations were performed considering a total time of $10 \mathrm{~h}$ of service at berth, segregated as follows:

- Time for the ship to be ready to get connected to the shore power source, $1 \mathrm{~h}$.

- Time for connection to the shore power source, $10 \mathrm{~s}$.

- The loading/unloading service, $8 \mathrm{~h}$.

- Time for disconnection from shore power source, $10 \mathrm{~s}$.

- Time for the ship to be ready to leave berth, 1 .

These 5 conditions were considered from the open-source data also from operational experience of field measurements previously performed on board ships by the authors. The same amount of time has been considered for the operations required by the ship to be ready to leave berth. The time spend loading/unloading was estimated in around $8 \mathrm{~h}$, based on operational experiences for a tanker ship, and the cargo capacity of the ship used for this study. The operational profile of the ship allows consideration of the 1-h time frame of being able to be connected to the onshore power source, as enough for the study purposes, demonstrating the applicability of the strategy. The time for the bi-directional power flow control strategy to be activated was calculated to be less than $10 \mathrm{~s}$.

Results are presented considering these 5 conditions, and emissions were properly estimated. Figure 7 presents the estimation of the $\mathrm{CO}_{2}$ emissions when applying the EEOI. The CI IN and CI OUT conditions lasted $10 \mathrm{~s}$ and are represented as the accumulation of emissions from the previous condition for the sake of graphical representation only.

The maximum $\mathrm{CO}_{2}$ emissions reach around 3.5 tons, when the ship is in loading/unloading services without the strategy being applied, which considers the auxiliary engines operating at maximum load with a high SFC. When the strategy is applied, simulation results show a reduction of the auxiliary engines load. In this condition, the auxiliary engines reach their MCR where the specific fuel consumption is minimum showing a reduction of about $20 \%$ of $\mathrm{CO}_{2}$ emissions compared to their performance without the applied strategy.

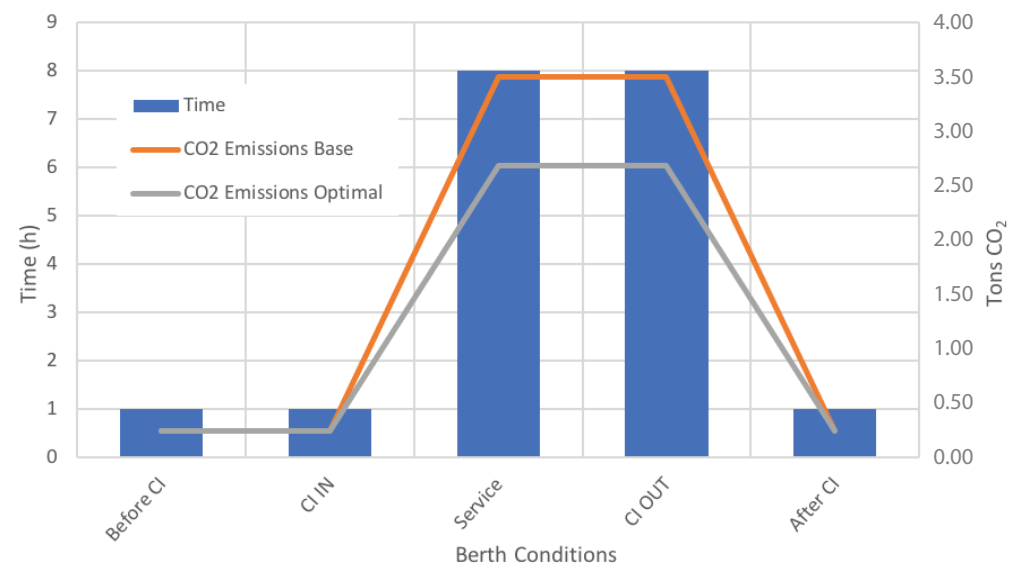

Figure 7. Auxiliary Engines $\mathrm{CO}_{2}$ emissions profile.

Figure 8 shows the results for the $\mathrm{NO}_{\mathrm{x}}$ emissions estimation. As presented, the maximum emissions reach around 0.09 tons when the ship is in loading/unloading services, without the strategy being applied. Because of the scale used, the differences are shown quite emphatic yet, and are in accordance with the specific fuel oil consumption and the auxiliary power demand, which are both maximums. When the strategy is applied, simulation results show a reduction of the auxiliary engine load. In this condition the auxiliary engines reach their MCR where the specific fuel consumption is minimum, showing a reduction of about $34 \%$ of $\mathrm{NO}_{\mathrm{x}}$ emissions, when compared to their performance without applying the control strategy. 


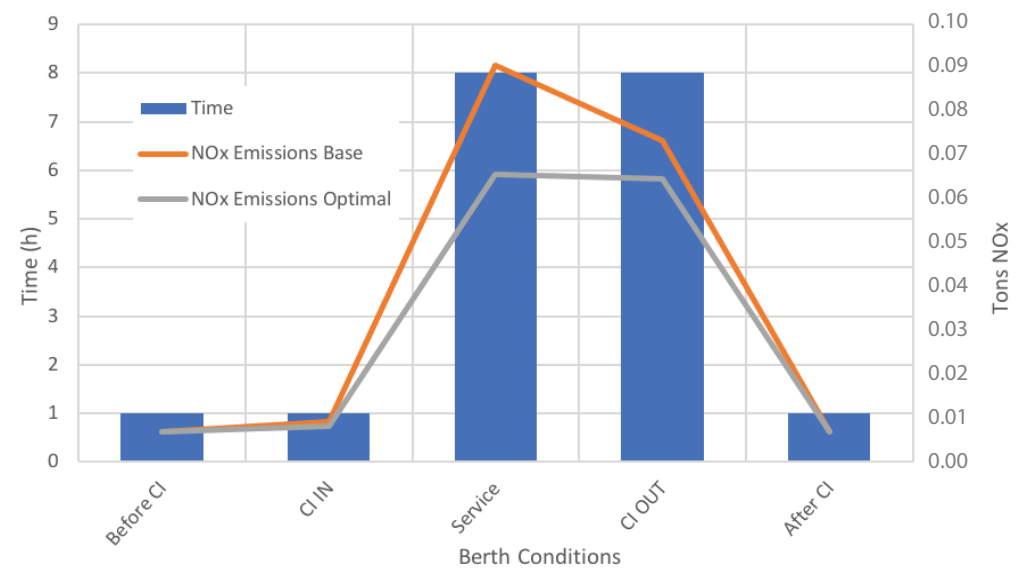

Figure 8. Auxiliary Engines $\mathrm{NO}_{\mathrm{x}}$ emissions profile.

Figure 9 shows the results for the $\mathrm{SO}_{\mathrm{x}}$ emissions estimation. As shown, maximum emissions reach around 0.02 tons when the ship is in loading/unloading services, without the strategy being applied. When the strategy is applied, simulation results show a significant reduction of the auxiliary engine load, thus the auxiliary engines reach their MCR where the specific fuel consumption is minimum, presenting a reduction of about $30 \%$ of $\mathrm{SO}_{\mathrm{x}}$ emissions compared to their performance without the applied strategy.

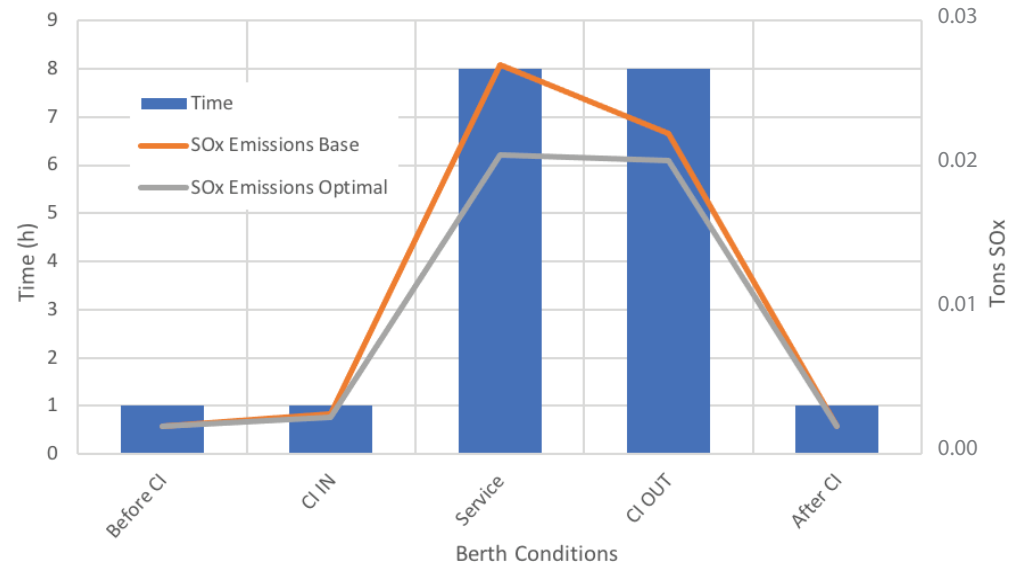

Figure 9. Auxiliary Engines $\mathrm{SO}_{\mathrm{x}}$ emissions profile.

The total amount of emissions being generated by the ship without and with the bidirectional power flow strategy, when applying cold ironing, are presented in Table 3. It is possible to appreciate the significant reduction in the global emissions when an appropriate strategy to control the power flow is used, which besides having the quantifiable impact on emissions, also has a significant impact in the operation of the ship while at berth: the auxiliary engines will be operating at their optimum load all the time, which in fact reduces the probabilities of failure associated with continuous operation away from the optimum load [26-29]. This is an important issue, because it relates the operational efficiency of the ship, which cannot only be considered through the propulsion system, but from the auxiliaries too. The auxiliaries are the on-board systems which support the propulsion machinery, providing an overall efficiency of the ship. 
Table 3. Emissions Comparison.

\begin{tabular}{lccc}
\hline Emissions & $\mathbf{C O}_{2}$ [Tons] & NO $_{\mathbf{x}}[$ Tons] & SO $_{\mathbf{x}}$ [Tons] \\
\hline Base Case & 8.001 & 0.248 & 0.061 \\
Optimized & 6.378 & 0.163 & 0.043 \\
Reduction [tons] & 1.623 & 0.084 & 0.018 \\
Reduction [\%] & $20 \%$ & $34 \%$ & $30 \%$ \\
\hline
\end{tabular}

\subsection{Power Converter Performance}

In this section, an evaluation of the b2b converter control scheme, using a MEPT algorithm, is presented. Simulation results include two different load steps at (1) and at (2), both representing different operational conditions of the on-board auxiliary engine $P_{x}$ @ 100\% of MCR as base condition before (1), $60 \%$ of MCR in (1), and finally going to $98 \%$ MCR at (2).

Figure 10 shows the performance of the shore supply, the performance of the $b 2 b$ converter, in terms of its controlled currents. At low high operational requirements over 95\% of rated power, the MEPT algorithm sets active power reference in shore-to-ship supply region, therefore the active power producing current $i_{d}>0$, whereas the reactive power producing current $i_{q}=0$. On the other hand, when entering a low load condition below the minimum SFC point, the MEPT, forces the power converter to operate in the ship to shore region, therefore the active power producing current $i_{d}<0$, while the reactive power producing current $i_{q}=0$.

The grid side currents dynamic performance is shown in Figure 11, showing rapid orientation, sinusoidal behavior and fast dynamic response, during the transition of operation mode at (1) and (2) respectively. Moreover, the fast-tracking dynamics of the optimization algorithm, ensures minimization on the current wave-form distortion.

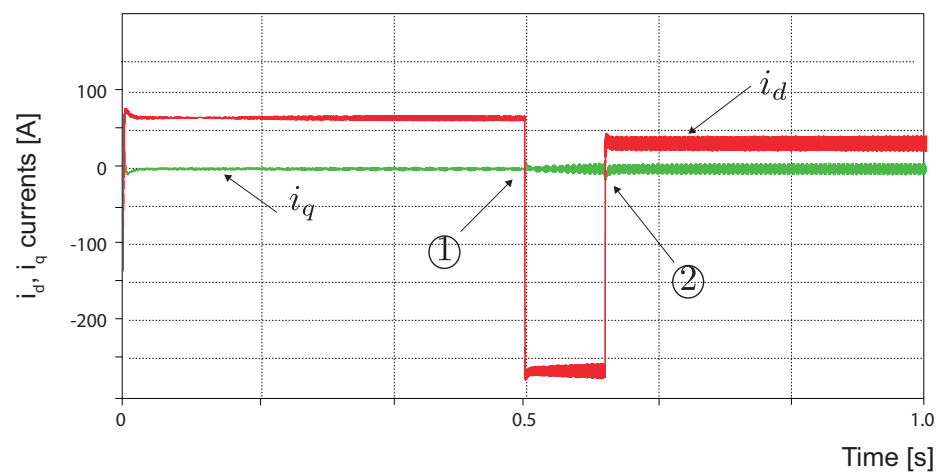

Figure 10. Shore supply converter control performance.

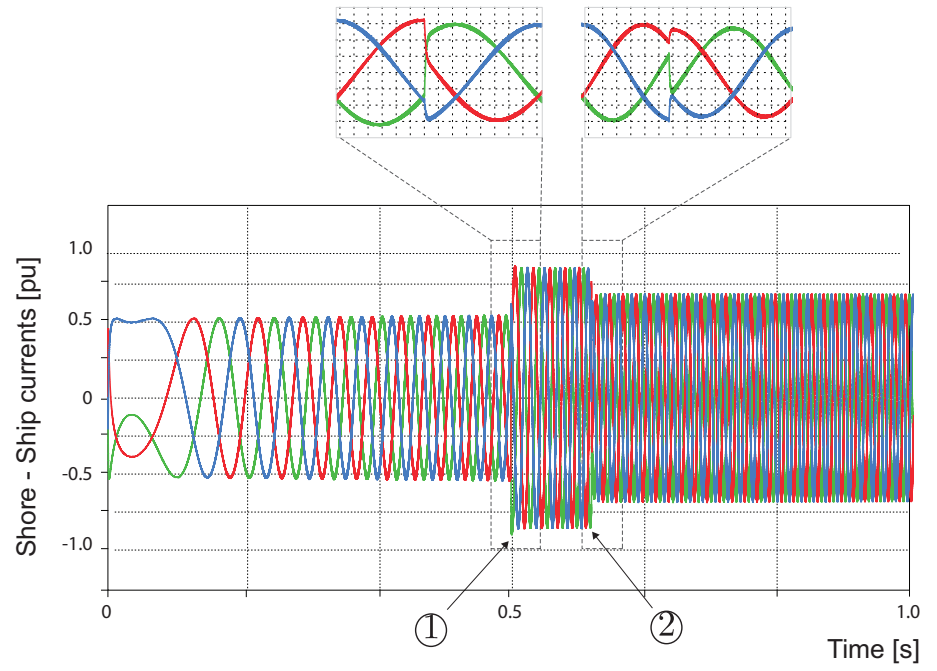

Figure 11. Shore supply converter output currents performance. 


\section{Discussion}

The applied strategy shows significant reduction in the specific fuel consumption of the auxiliary engines. Results are showing great assertiveness and accuracy to be further applied for longer periods. In this context, longer periods mean a full loading/unloading profile considering i.e., time at night when loading/unloading is not allowed or when personnel shifts are carried out. These and other operational situations making the time at berth being larger, therefore allowing for the auxiliary engines and the shore power to work synchronized. This work provided the best performance of the ship and the port, to mitigate the effect of excessive emissions generation that an operation.

The use of EEOI from the IMO only considers $\mathrm{CO}_{2}$ emissions, yet other mandatory regulations from the $\mathrm{IMO}$ are considering the estimation of the $\mathrm{NO}_{\mathrm{x}}$ and $\mathrm{SO}_{\mathrm{x}}$ emissions too. The $\mathrm{NO}_{\mathrm{x}}$ emissions over specific rules, considering the actual performance of the engine, and for $\mathrm{SO}_{\mathrm{x}}$ emissions, over specific rules of sulfur content of the fuel consumed by ships when navigating and while at port. These rules were considered for the emissions estimation methodology.

Other emissions such as carbon monoxide (CO) and particulate matter (PM) are also generated by consuming fossil fuels, but they do not have a specific approach to be estimated by the IMO, and therefore were not quantified in this study. Nonetheless, the methodology allows consideration of $\mathrm{CO}$ and PM emissions and are going to be part of the future work, to get the full spectrum of emissions that could be reduced when applying a bi-directional power flow control strategy. The strategy over cold ironing must be considered to be a short-term port-based emission-reduction technology, proposed from the IMO to reduce the impact of shipping.

\section{Conclusions}

The applied strategy shows reduction in the specific fuel consumption of the auxiliary engines, thus reducing emissions in $20 \%$ for $\mathrm{CO}_{2}, 34 \%$ for $\mathrm{NO}_{\mathrm{x}}$ and $30 \%$ for $\mathrm{SO}_{\mathrm{x}}$.

Results for the proposed cold-ironing power configuration, show great assertiveness and accuracy to be further applied for longer periods of ship operation while at berth.

The control scheme, when simulating the proposed cold-ironing configuration performance in the shore-to-ship operating region, makes the on-board auxiliary engine work closer to the MEOP, which leads to lower SFC, therefore contributing to low operational emissions.

The implemented power converter control scheme shows high reliability and accuracy to follow the optimization algorithm, with good dynamic performance, at both operating conditions. It also ensures bi-directional power flow, with low distortion in the shoreside currents.

The perturb and observe algorithm presents an accurate performance to obtain a local search for the minimum emissions point, starting at a random state. Future results may include the use of an adaptive perturbation function to ensure full convergence when reaching the minimum emissions point.

Author Contributions: Conceptualization, C.A.R.; methodology, C.A.R. and J.R.P.; software, C.A.R.; validation, C.A.R. and J.R.P.; formal analysis, C.A.R. and J.R.P.; investigation, C.A.R. and J.R.P.; data curation, J.R.P.; writing-original draft preparation, C.A.R. and J.R.P.; writing-review and editing, C.A.R. and J.R.P. All authors have read and agreed to the published version of the manuscript.

Funding: This research received no external funding.

Institutional Review Board Statement: Not applicable.

Informed Consent Statement: Not applicable.

Acknowledgments: The authors wish to thank the support of the Electrical Engineering School, Pontificia Universidad Catolica de Valparaiso.

Conflicts of Interest: The authors declare no conflict of interest. 


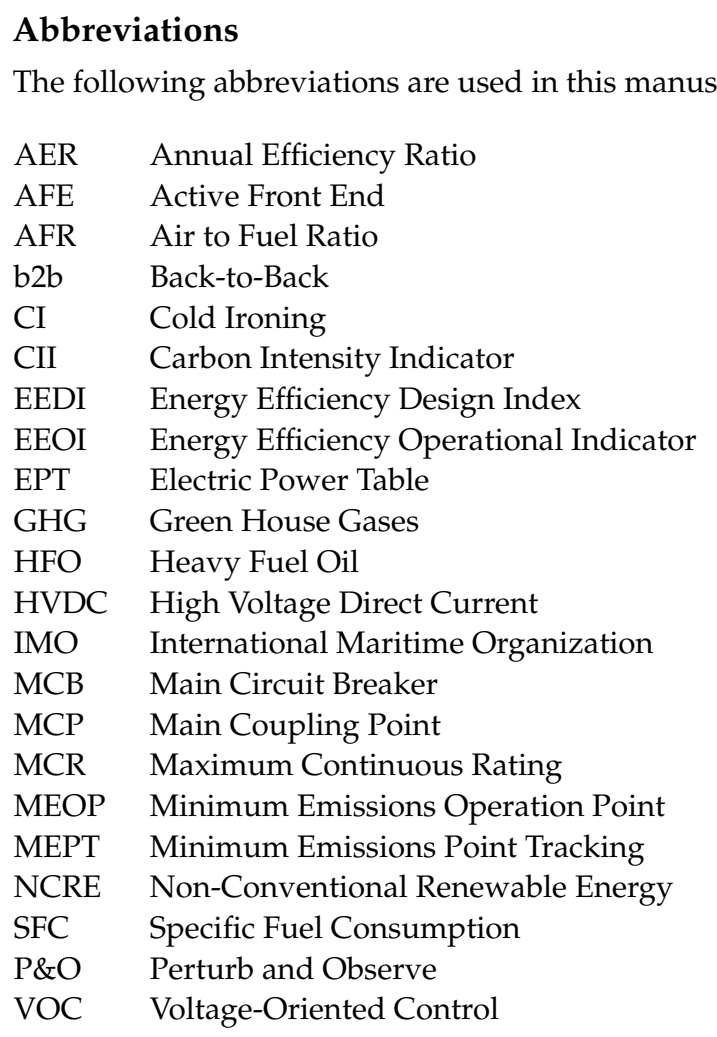

\section{References}

1. Patel, M.R. Shipboard Electrical Power Systems; CRC Press: Boca Raton, FL, USA, 2012.

2. Zis, T.P.V. Prospects of cold ironing as an emissions reduction option. Renew. Sustain. Energy Rev. 2019, 119, 170-182. [CrossRef]

3. International Maritime Organization. Initial IMO Strategy on Reduction of GHG Emissions from Ships; International Maritime Organization: London, UK, 2018.

4. Bouman, E.; Lindstad, E.; Rialland, A.; Strømman, A. State-of-the-Art Technologies, Measures, and Potential for Reducing GHG Emissions from Shipping-A Review. Transp. Res. Part Transp. Environ. 2017, 52, 408-421. [CrossRef]

5. Chatzinikolaou, S.D.; Oikonomou, S.D.; Ventikos, N.P. Health Externalities of Ship Air Pollution at Port-Piraeus Port Case Study. Transp. Res. Part Transp. Environ. 2015, 40, 155-165. [CrossRef]

6. Iris, C.; Lam, J.S.L. A review of energy efficiency in ports: Operational strategies, technologies and energy management systems. Renew. Sustain. Energy Rev. 2019, 112, 170-182. [CrossRef]

7. Tang, R.; Wu, Z.; Li, X. Optimal operation of photovoltaic/battery/diesel/cold-ironing hybrid energy system for maritime application. Energy 2018, 162, 697-714. [CrossRef]

8. International Maritime Organization. Guidelines on the Method of Calculation of the Attained Energy Efficiency Design Index (EEDI) for New Ships; International Maritime Organization: London, UK, 2018.

9. International Maritime Organization. Guidelines for Voluntary Use of the Ship Energy Efficiency Operational Indicator (EEOI); International Maritime Organization: London, UK, 2009.

10. International Maritime Organization. Guidelines for the Development of a Ship Energy Efficiency Management Plan (SEEMP); International Maritime Organization: London, UK, 2016.

11. IEC/IEEE International Standard-Utility Connections in Port-Part 1: High Voltage Shore Connection (HVSC) Systems-General Requirements; IEC/IEEE 80005-1:2019; International Electrotechnical Commission: Washington, DC, USA, 2019; pp. 1-78. [CrossRef]

12. Paul, D.; Peterson, K.; Chavdarian, P.R. Designing Cold Ironing Power Systems: Electrical Safety During Ship Berthing. IEEE Ind. Appl. Mag. 2014, 20, 24-32. [CrossRef]

13. Armstrong, V. Vessel Optimisation for Low Carbon Shipping. Ocean Eng. 2013, 73, 195-207. [CrossRef]

14. Armstrong, V.; Banks, C. Integrated Approach to Vessel Energy Efficiency. Ocean Eng. 2015, 110, 39-48. [CrossRef]

15. Fiadomor, R. Assessment of Alternative Maritime Power (Cold Ironing) and Its Impact on Port Management and Operations. Master's Thesis, World Maritime University, Malmö, Sweden, 2009.

16. Nagel, S.; Khouri, J.; Mast, R. Berth 121 Cold Ironing Project. In Proceedings of the 11th Triennial International Conference on Ports, San Diego, CA, USA, 25-28 March 2007.

17. Peterson, K.L.; Chavdarian, P.; Islam, M.; Cayanan, C. Tackling ship pollution from the shore. IEEE Ind. Appl. Mag. 2009, 15, 56-60. [CrossRef] 
18. Ali, A.; Almutairi, K.; Padmanaban, S.; Tirth, V.; Algarni, S.; Irshad, K.; Islam, S.; Zahir, M.H.; Shafiullah, M.; Malik, M.Z. Investigation of MPPT Techniques Under Uniform and Non-Uniform Solar Irradiation Condition-A Retrospection. IEEE Access 2020, 8, 127368-127392. [CrossRef]

19. Kolesnik, S.; Kuperman, A. On the Equivalence of Major Variable-Step-Size MPPT Algorithms. IEEE J. Photovoltaics 2016, 6, 590-594. [CrossRef]

20. Friedli, T.; Kolar, J.W.; Rodriguez, J.; Wheeler, P.W. Comparative Evaluation of Three-Phase AC-AC Matrix Converter and Voltage DC-Link Back-to-Back Converter Systems. IEEE Trans. Ind. Electron. 2012, 59, 4487-4510. [CrossRef]

21. Flourentzou, N.; Agelidis, V.G.; Demetriades, G.D. VSC-Based HVDC Power Transmission Systems: An Overview. IEEE Trans. Power Electron. 2009, 24, 592-602. [CrossRef]

22. Rodríguez-Cabero, A.; Sánchez, F.H.; Prodanovic, M. A unified control of back-to-back converter. In Proceedings of the 2016 IEEE Energy Conversion Congress and Exposition (ECCE), Cincinnati, OH, USA, 1-5 October 2016; pp. 1-8. [CrossRef]

23. Rahoui, A.; Bechouche, A.; Seddiki, H.; Abdeslam, D.O. Grid Voltages Estimation for Three-Phase PWM Rectifiers Control Without AC Voltage Sensors. IEEE Trans. Power Electron. 2018, 33, 859-875. [CrossRef]

24. Baggu, M.M.; Chowdhury, B.H.; Kimball, J.W. Comparison of Advanced Control Techniques for Grid Side Converter of DoublyFed Induction Generator Back-to-Back Converters to Improve Power Quality Performance During Unbalanced Voltage Dips. IEEE J. Emerg. Sel. Top. Power Electron. 2015, 3, 516-524. [CrossRef]

25. Clarksons. Clarksons World Fleet Register 2020. Available online: http:/ /www.clarksons.net/wfr/ (accessed on 30 October 2020).

26. Calder, N. Marine Diesel Engines: Maintenance, Troubleshooting, and Repair; Adlard Coles Nautical: London, UK, 2007.

27. Cowley, J. The Running and Maintenance of Marine Machinery; Institute of Marine Engineers: London, UK, 1992.

28. MAN Diesel \& Turbo. Operation on Low-Sulphur Fuels MAN B\&W Two-Stroke Engines; MAN Diesel \& Turbo: Copenhagen, Denmark, 2014.

29. MAN Diesel \& Turbo. Retrofit and Upgrade; MAN PrimeServ Products and Services Portfolio; MAN Diesel \& Turbo: Copenhagen, Denmark, 2020. 